\title{
Francis Bacon's Use of Ancient Myths in Novum Organum
}

\author{
Wendell P. MacIntyre \\ University of Prince Edward Island
}

\begin{abstract}
Francis Bacon's monumental work, Novum Organum, is an attempt to establish a new status for mankind. Using some of the most prominent myths-particularly those dealing with the gods Pan, Dionysius, Perseus, and Prometheus-Bacon hoped to inaugurate a new era of success and happiness for his fellow man. In Book I of Novum Organum, Bacon involves these gods and their significances, juxtaposing them with man as he might and could be. In this essay, the author examines about twenty of the "Aphorisms" in Bacon's work, showing the possible impact of the ancient god who is most appropriate for the "Aphorisms" under discussion. This article is clearly a work of utopian proportions, revealing fascinating journeys into the realm of romanticism.
\end{abstract}

In this paper, I will show how the ancient myths of Pan, Perseus, Dionysius, and Prometheus have an impact on Book I of Francis Bacon's Novum Organum. This research has been carried out by making an intensive cross-referencing of Bacon's analysis of myths in his work, The Wisdom of the Ancients, with his Novum Organum. A selected number of aphorisms from the Novum Organum are used in this study. In these aphorisms, one can detect traces-sometimes subtle, sometimes more overt-of the characteristics, functions, and influence of the mythical gods mentioned at the beginning of this paper. First, a few words about Bacon's interest in myths is in order. Bacon was fond of involving ancient myths in his extensive efforts to focus man's attention on the beneficent power and value of nature-external nature - the world around us, a study which he would call natural philosophy. In the preface to his Wisdom of the Ancients, Bacon says:

I mean the employment of parables [myths] as a method of teaching, whereby inventions that are new and abstruse and remote from vulgar opinions may find an easier passage to the understanding. On this account it was that in the old times when the inventions and conclusions of human reason ... were as yet new and strange, the world was full of all kinds of fables, and enigmas, and parables, and similitudes: and these were used not as 
a device for shadowing and concealing the meaning but as a method of making it understood.... (Works 80)

As an illustration of a long-lost past, myths/fables, in Bacon's view, could return man to his prelapsarian state, and give back to him his power over created things. Translated into terms more relevant to Bacon's Natural Philosophy, this means that, unlike Plato, who wished to make man a slave of Philosophy, Bacon would have Philosophy serve man; that is, Natural Philosophy would become the servant of man. Plato tried to deify man in his Platonic Philosophy, which put elaborate stress on the spiritual or supernatural component of the human complex. Conversely, Bacon preferred seeng man maintain his natural status, while providing him with whatever he needed to be and to remain man. Bacon's intention was never to make man perfect; rather, his ideal was to render imperfect man more comfortable.

In Bacon's view, myths were embodiments of an ancient wisdom which preceded Hesiod and Homer; and, these myths, Bacon insisted, must be recapturcd. Bacon emphasizcs that in these ancient, mythical times, man, though fallen, had somehow regained control over nature, and had begun to enjoy something akin to prelapsarian bliss, even if still groping in a postlapsarian condition. Moreover, Bacon would say that, before the age of Plato and Aristotle, man was beginning to revive from the universal collapse of human nature. This was because he was studying the works of God in the universe of nature which surrounded him. Bacon felt that ancient myths contained hidden knowledge about the relationship of man and nature and of man and God. He also entertained the theory that a generation of wise men once flourished on the earth who explained the mysteries of nature through the medium of parables and myths. Bacon's Novum Organum, a part of his Great Instauration, was an attempt to renew and restore man's place in the universe through the study of Natural Philosophy. "Knowledge," Bacon thought, "depends on a certain relationship between the mind of man and the world of Nature" (Levine 84).

The Novum Organum seems to imitate the serious and mysterious tone of the ancient fables or myths. Interlacing statements about the interpretation of nature with traces of ancient myths, Bacon seemed eager to set man on a path which would lead him to a greater and more systematic knowledge of external nature. First, let us discuss the god Pan, the biform (human and brute) son of Mercury, or of Penelope, or of Jupiter and Hybris. Pan has been associated with creation, with the study of nature, which is really Bacon's subject in his Novum Organum. Pan is said to have sprung from the Divine Word who, of course, was the prime cause of the creation of the world.

In aphorism 42, Bacon refers to the "Idols of the Cave," a group who tend to interpret nature according to their own particular intellectual strengths. These searchers of knowledge--specialists-adhere to their personal beliefs, defying, and seemingly fearing opposite views. Their understanding, which Bacon feels is clouded with false notions, isolates them, causing them to become cave-like sects who embrace somewhat maverick criteria in their approach to knowledge: "... men look for sciences in their own lesser worlds, and not in the greater or common world" (NO 49). The behaviour of the "Idols of the Cave" seems to illustrate one of the features or functions of the god Pan, who, among other feats, could cause terror or panic. Pan was able to foment fear, and, in the context 
of aphorism 42, he might well be filling the disciples of the "Idols of the Cave" with a fear of those who scorn specialization. The "Idols of the Cave" followers reject the pursuit of universal knowledge, preferring to ride their own hobby horses. Here again, the myth of Pan is relevant. Pan, denoting the universe of nature, and, therefore, symbolizing a wide or open approach to everything, would scarcely favor the narrow views of the "Idols of the Cave."

Bacon observed how superstition was corrupting philosophy. That is, he felt that there was a contrived mingling of human and divine elements, which resulted in fantastic philosophy and specious, even heretical, religion. Bacon elaborates on this situation in aphorism 65, which is a rationalist's defense against false and pretentious learning. This aphorism is an exposition of the aberrations of human understanding and imagination. Bacon deplores the endorsing of final causes (the ultimate uses or purposes of knowledge), which avoids a consideration of immediate causes (the practical uses of knowledge), an obvious reference to the need for Bacon's method of philosophical induction; that is, a study about how knowledge grows and advances from particulars (bits, or items of knowledge), on to axioms or principles of knowledge. The substance of aphorism $65 \mathrm{might}$ remind one again of Pan whose left hand supported a sheep-hook which was rounded at the top. The sheep-hook of Pan represents the straight and crooked ways of nature. One might suggest, then, that the negative impact of superstition on natural philosophy shows how the crooked or erroneous interpretations of nature are impeding the progress of natural knowledge. Pan also carried seven reeds in his right hand, and these reeds signified harmony. Pursuing this symbolism, one might suggest that if natural knowledge were allowed to develop without the interference of superstition, harmony might then prevail. That is to say, that the seven reeds of harmony held by Pan would offset the effects of Pan's curved sheep-hook. In other words, let natural philosophy be allowed to advance and flourish. Moreover, remembering that Pan was sprung from the Divine Word, one would conclude that he would favor peace and harmony, the peace and harmony contributing to, and flowing from, an uninhibited and uncontaminated study of natural philosophy.

Bacon feared that a flooding of particulars (items of knowledge) in men's minds might prevent a consolidating of knowledge. He refers, in aphorism 104, to the mind's flitting about from this to that particle of knowledge, shying away from arrangement and organization. "The understanding must not therefore be supplied with wings, but rather hung with weights, to keep it from leaping and flying" (NO 98); aphorism 104, from which this excerpt is taken, reminds one of the Pagasus myth. Pegasus, the winged horse-shaped god, emerged from the death wound of Medusa which was inflicted by Perseus. Pegasus was a victorious emblem in ancient wars. He was also the horse of the muses who were carried about, inspiring this or that writer to meet and control a literary challenge. In aphorism 104, Bacon sees men flying from particular to particular, caring little about solidifying knowledge. He sees them seeking victory over knowledge by simply flying, like Pegasus, from one piece of knowledge to another. The god Pan is relevant in a discussion of aphorism 104 as well. Pan is the god of hunters, among his many functions; in this case, he is the god of hunters of knowledge. However, in aphorism 104, the hunters of knowledge sought only bits and pieces of knowledge. They hunted simply for the sake of hunting; they were not interested in assembling, and consolidating knowledge. In 
aphorism 92, Bacon is concerned about man's creeping despair as he pursues natural knowledge, and he fears that man gives up too easily. Such men are bothered by such preoccupations as: ". . . the obscurity of nature, the shortness of life, the deceitfulness of the senses, the weakness of the judgment, the difficulty of experiment ..." (NO 90-91). Bacon offers solace for such despair, by placing man within the orbit of divine providence, whom he calls the "author of good and Father of Lights" (NO 91-92). Bacon refers to the Prophet Daniel in this aphorism, and quotes from the Book of Daniel: "Many shall go to and fro, and knowledge shall be increased" (NO 92), implying that the advancement of knowledge and the unfolding of the universe go hand in hand.

Implicit in all of this is Bacon's attempt to reconcile human nature with the progress of knowledge. He sees man as being a dichotomy of body and spirit, and both of these are engaged in a mutual warfare, both competing for prominence in their respective pursuits. Pan is helpful here to explain the predicament of man as Bacon observes it. Pan, as mentioned earlier, was a biform, human in his upper part, and brute in his lower half. As Bacon dwells on the forces which interfere with man's quest for knowledge in aphorism 92, he seems to suggest that man's lower human nature (the brute part) endangers or retards the pursuit and acquisition of truth. In other words, the "deceitfulness of the senses," which Bacon mentions in this aphorism, can lure man's understanding away from its scarch for particulars, to say nothing about its attempt to establish principles and axioms, or its consolidating of these into valuable deposits of knowledge. So, Pan hovers over the hunters of knowledge, and his human-brute components can commplicate man's progress towards a more intimate acquaintance with nature which encircles him. As Bacon proceeds in his Great Instauration, in his monumental work Novum Organum, he cautions that he never intended to establish a new school or sect of philosophy. Rather, he simply envisioned a system which would extract causes, particulars, and axioms of knowledge through a study of nature. He hoped to found and shape what he called a natural philosophy which would be based on an inductive method of reasoning which leads from effects to causes, rather than from causes to effects - deductive method. In aphorism 106, Bacon outlines the objectives of his natural philosophy: "My purpose ... is to try whether I cannot in very fact lay more firmly the foundations and extend more widely the limits of the power and greatness of man" (NO 106). Clearly, Bacon focuses on man, the individual, the living embodiment of infinite potential. Man is Bacon's subject, whose mind and body he hopes to harmonize through a systematic and palatable rendering of knowledge flowing from a study of the world around him, "sowing in the meantime for future ages the seeds of a purer truth, and performing my part toward the commencement of the great undertaking" (NO 106). As Bacon extols the great potential greatness of man, the microcosm in the midst of nature, one is again reminded of the god Pan. Pan, the emblem of creation, the counsellor and interpreter of the truths of external nature, seems relevant here. The god Pan was a horned creature, and his horns were broad at the base and pointed at the top. Let us recall that, in aphorism 116, Bacon spoke of laying "more firmly the foundations and extend more widely the limits of the power and greatness of man" (NO 106). The broad base of Pan's horns could represent Bacon's envisioned establishing of man within the curriculum of his Great Instauration and Novum Organum, rooting man firmly in a love for, and a diligent search for, natural truth. From this foundation, man 
could extend his quest, like Pan's soaring horns, for more and more knowledge. Pan's horns came to a point at the top, symbolically merging with infinity. Likewise, man's abilities are infinite, as is his quest for knowledge. As he becomes more and more informed, as he acquires more and more particulars, forms more and more axioms, and consolidates more and more truths, he rises, like Pan's horns, into the orbit of infinity. Inductively progressing, then merging finally with eternal truths, man's argosy to natural knowledge achieves its union with the ultimate cause and source of truth.

The god Perseus, linked with strategic and just wars, the destroyer of Medusa, a true Friend of the Graeae (war's sisters), and the victor over tyranny, may be correlated with Bacon's Novum Organum. In the military phase of his career, Perseus was guided by three principles: (1) not to subjugate nations recklessly; (2) to ensure that the cause of war was just; (3) not to pursue vast projects. Apart from his war philosophy, Perseus displayed other features or characteristics which seem to have had an impact on Bacon's Novum Organum. In order to destroy Medusa, Perseus was equipped with appropriate mechanisms. Mercury gave him wings for his feet, the gift of speed. From Pluto he acquired a helmet, the gift of counsel. He got a mirror and shield-the gift of foresight-from Pallas. The Graeae gave him their one eye and one tooth, signifying, respectively, a means to discover information, and to stir people's minds. In aphorism 19, Bacon speaks of ways to discover truth: one flying from the senses and particulars to general axioms or principles; the other deriving axioms/principles from the senses, arriving at general axioms. Bacon favors the latter method of acquiring knowledge. Man's flying from the senses; that is, failing to acknowlege that the senses can be a means of acquiring knowledge reminds one of Pegasus's approach to a military challenge. In his Wisdom of the Ancients, where Bacon speaks of Pegasus, he explains that swiftness is more effective in the second attack; that is, in the follow-up to the first attack. Applying this aspect of the Pegasus myth to aphorism 19, one might suggest that man's flying from the senses represents his first impetuous assault on knowledge, which should be followed up by a more concentrated evaluation of what the senses can contribute to the process of knowledge.

In aphorism 35, Bacon describes how confidently and calmly the French invaded Italy in one of their military expeditions. He uses this historical episode to suggest that, like the French soldiers, those capable of absorbing his theories of knowledge should do so calmly. In his Wisdom of the Ancients, while discussing the war theme of the Perseus myth, Bacon says that one should not be too eager to overcome neighboring nations. Applying this idea to aphorism 35, one might infer that Bacon does not want his theories about natural philosophy to bombard the minds of everyone: "I . . . would have my doctrine enter quietly into the minds that are fit and capable of receiving it..." (NO 46). Still referring to Bacon's treatment of Perseus in The Wisdom of the Ancients, one finds that Perseus favors the concept of a just war, one which overthrows tyranny. One might detect here-at least indirectly-something of Bacon's enduring antipathy towards some of Aristotle's principles and theories of knowledge. Bacon blamed Aristotle for using postlapsarian man as a plaything in his syllogistic process of deductive reasoning. So, Bacon, with the help of the Perseus myth, was eager to free man from the tyranny of Greek philosophy, and bring him into the domain of inductive reasoning. This would constitute a just cause for 
Bacon's attack on theories of knowledge alien or even hostile to his principles of natural philosophy.

The god Perseus was given a mirror and shield by Pallas who, incidentally, stands for providence; these instruments symbolize two kinds of insight: one which protects against the enemy; the other which spies into the forces and movements of the opponent. Bacon's aphorism 38, in his Novum Organum, seems to have traces of Perseus's mirror-and-shield combination. In this aphorism, Bacon describes the condition of men's minds which are plagued with false notions or idols. Like Perseus with his mirror, Bacon seems to spy into the minds of those who are influenced by the enemies of truth, finding there a solid phalanx of error. However, even after he discovers this misfortune, and after trying to dislodge the enemy with his own system and process of knowledge, the enemy will still not surrender. Rather it will continue its assaults, a situation which calls for self-defense on the part of those attempting to learn about his inductive philosophy. The idols and false notions '. . . not only so beset mens' minds that truth can hardly find entrance, but . . . they will again in the very instauration of the sciences meet and trouble us, unless men being forewarned of the anger fortify themselves as far as may be against their assaults" (NO 47) In this quotation from Aphorism 38, we have a useful example of the function of Perseus's shield. Bacon, like Perseus, assesses the tyrannical forces of error, and decides that there is here a just cause for a counter attack. He attacks with truths, and meets continuing opposition, against which he must shield himself.

Bacon speaks of the "Idols of the Tribe" in his Novum Organum. In aphorism 41, he mentions those who place excessive emphasis on their own human nature, and who insist that their senses are the measure of things: "... the human understanding is like a false mirror, which, receiving rays irregularly, distorts and discolors the nature of things by mingling its own nature with it" (NO 48). The Perseus myth seems relevant here, as well. In The Wisdom of the Ancients, Bacon describes Perseus using his mirror to discover the activities of the enemy, in order to plan appropriate strategy for his assault on their positions. However, in the context of aphorism 41, the "Idols of the Tribe" look inward rather than outward, placing undue value on their senses. Subconsciously, they were focusing on the apparently unknown enemy within themselves, an inordinate reliance on their own human natures as sources of knowledge. Their Perseus mirror could have reflected their erroneous approach to natural knowledge. One cannot resist involving the god Pan at this juncture. Pan's hair, made of many bristles, was compared to rays of light emitting from Pan's biform body. The "Idols of the Tribe" deflect the rays issuing from Pan, thereby rejecting Bacon's proper approach to knowledge, which he elucidated in his interpretations and theories of natural philosophy. After Perseus befriended the Graeae (war's sisters), whose power was located in the single eye and tooth which they mutually share, they gave Perseus their eye and tooth. This eye and truth symbolize, respectively, the power to discover information, and the power to sow rumors and stir up people's minds.

If one examines aphorism 56, he finds Bacon describing two factions: one which sides with antiquity, and one which favors modern systems or sources of knowledge. Bacon finds that these two factions are criticizing each other, apparently unwilling to bring about a compromise, or to adopt what Bacon calls a rational mean. The partisan behaviour of 
these competing forces might remind us of the Perseus myth. Like Perseus, who stood for war, among other things, the sponsors of antiquity and the moderns were engaged in mutual conflict. However, and contrary to Perseus's principles, they were clearly participating in an irrational and unjust war. Moreover, they remind us of the gifts of eye and tooth which Perseus received from the Graeae. Sponsors of antiquity and of the moderns, using the eye of Perseus, were eager to discover information. However, using Perseus's tooth, they fomented envy, stirring up the minds of their opponents, culminating in a kind of chaos. Like Perseus again, they fly with wings in their feet, dashing recklessly into different sources of knowledge, forgetting -in consort with the Perseus myth-that the follow-up or more rational attack on knowledge would be more fruitful than the rather ineffective first encounter.

It was Bacon's fervent hope that human life might profit from new discoveries and new sources of intellectual power. Nurturing this ideal, he expected civilization to progress and improve. In aphorism 111, Bacon touches on the potential of men's minds, and on how men sometimes use their intelligence, time, and skills in the pursuit of matters which are of little value. He would prefer that they expend their talents in more substantial studies.

The god Dionysius, often linked with the progress of civilization and a lover of peace, could be connected with Bacon's dream of a great instauration, or of a new organum. In aphorism 111, Bacon says that if men pursued "sound and solid studies, there is no difficulty that might not be overcome" (NO 103). Dionysius's mother Semle, obliged her paramour, Jupiter, to grant her whatever she desired. He acceded to her request; however, in the midst of their amorous embrace, Semle was scorched to death, and the child in her womb, who would later be named Dionysius, was subsequently looked after by Jupiter. Could we not speculate-even if this might seem a bit far-fetched-that Dionysius, presumably reproducing his father's (Jupiter's) determination and loyalty, might represcnt or prefigure Bacon's unrelenting dedication to the pursuit of his objective: to set mankind on its way to a cultivation of the works of nature?

Dionysius is traditionally made interchangeable with the god Bacchus, the god of wine, passion, and desire. Passion and desire are rarely satisfied with what they have achieved; they avidly seek new goals. In aphorism 48 , Bacon enlarges on the tendency of the human understanding to seek other truths, beyond itself, and not yet reached. "The human understanding is unquiet; it cannot stop or rest, and still presses onward, but in vain ..." (NO 51). Like Dionysius, the champion of unlimited desire, man habitually searches for more and more knowledge. However, this can easily become simply a matter of accumulating knowledge, an exercise in personal satisfaction.

While Dionysius, or Bacchus, is historically associated with wine, he also promotes the social and beneficient effects of wine. Through the medium of wine, Dionysius/Bacchus hoped to engender peace and a stimulating of culture or civilization. Dionysius's role as a promoter of peace may be related to Bacon's aphorism 93. Here, Bacon traces everything to its divine origin, the source of goodness and light. "The beginning is from God: for the business which is in hand, having the character of good so strongly impressed upon it, appears to proceed from God, who is the author of good, and the Father of Lights" (NO 91-92). The wine of Bacchus, like the wine mentioned in the scriptures, can bring joy to men's hearts. Let us say that Dionysius and the divine author of the universe share 
attributes of joy and peace. Mythologically and theologically, the universe of nature and the pursuit of natural knowledge may both be traced to a common source of joy, harmony, and peace.

In The Wisdom of the Ancients, Bacon reminds us that the god Dionysius came back to life after his death, a feat which should not go unnoticed in any discussion about the universe and the knowledge of nature. Dionysius is symbolic of a resurrection of joy and peace. Joy, peace, and the progress of civilization are indestructible. They revive and live on, thereby imitating the immortal properties of the divine creator and redeemer of the universe. Dionysius is also related to the desire or appetite for apparent good, for what appears sufficiently satisfying. He is therefore associated with the tendency to pursue and grasp truths rashly, without carefully analyzing what has been grasped. In aphorism 72, Bacon mentions the precipitous willingness with which men subscribe to the teachings of Aristotle. In keeping with the Dionysian myth, these people hasten to accept what Aristotle tells them without criticism or analysis. "But far the greater number of those who have assented to the philosophy of Aristotle have addicted themselves thereto from prejudgment and upon the authority of others ..." (NO 74).

The Dionysius/Bacchus myth reveals that the favored tree of Dionysius was the Ivy. Ivy connotes clinging, spreading, and the ability to survive in winter. In aphorism 86 , while speaking of man's attraction to knowledge, Bacon describes the behaviour of those who run into the arms of beckoning knowledge. "For if you look at the method of them, and the divisions [of knowledge], they seem to embrace and comprise everything which can belong to the subject" (NO 84). Dionyius's Ivy tree helps describe these types who cling to knowledge, embracing what they have discovered. Moreover, they display what they have acquired, and try to make it attractive to those around them. In effect, they disseminate or spread their new-found knowledge, thus resembling the adhesive and spreading features of the Ivy tree of Dionysius. Again, like the Ivy, which survives in winter, rejected by the cold-rejected by nature, by experience-men who tenaciously hold on to knowledge, from whatever source, might be rejecting or ignoring another tradition or experience, whose tenets might repel their particular approach to knowledge. "And although these divisions [of knowledge] are ill filled out and are best as empty cases, still to the common mind they present the form and plan of a perfect science" (NO 84). In other words, the common mind-that is, the undisciplined, uncritical mind-like Dionysius's Ivy tree, embraces knowledge indiscriminately. Such action would be rejected-like the cold resisting the Ivy-by a more analytical group of knowledge-seekers, whom Bacon mentions in this same aphorism, aphorism 86: "But the first and most ancient seekers after truth were wont, with better faith and better fortune, too, to throw the knowledge which they gathered from the contemplation of things, and which they meant to store up for use, into aphorisms" (NO 84).

I will conclude this paper with some references to the god Prometheus, who, because of his special powers and prerogatives, sums up Bacon's enormous faith in, and hope for, mankind. The god Prometheus stands for the state or composition of man-mind and intellect, along with his human nature. In the Promethean tradition, man is the very centre of the world, the master of creation which, in turn, is at his service. In The Wisdom of the Ancients, Bacon states that Prometheus created man out of clay, an achievement which has 
equated him with providence. Prometheus is also linked with the origin of fire on earth. It is reported that he once ascended to heaven with fennels which he lighted at the sun's, chariot, subsequently bringing the new fire back to earth. Later, torch-races were inaugurated in his honor.

Bacon affirms what he wants to do for man in aphorism 116: "My purpose ... is to try whether I cannot in very fact lay more firmly the foundations and extend more widely the limits of the power and greatness of man" (NO 106). This sounds like Promethean doctrine as it clearly focuses on the magisterial and predominant position of man in the universe. In other aphorisms, aphorisms 81 and 82 , for example, Bacon seems to be hinting at the role of Prometheus: "It is not possible to run a course aright; when the goal itself has not been rightly placed" (NO 78). Here, we might get an image of a Promethean torch-race, going this way and that way, displaying much fire, but without distinct goals or purposes. It is an illustration of a search for knowledge which is more emotional than scientific, and somewhat irrational. In another section of aphorism 82, Bacon speaks of lighting the way to the acquisition of knowledge: "But the true method of experience ... first lights the candle, and then by means of the candle shows the way..." (NO 79-80). Notice that Bacon says "shows the way," which assumes that he who searches for knowledge is first enlightened about what he is seeking; that is, he knows how and where to find knowledge, presumably, knowledge from nature, in keeping with Bacon's cherished system of natural philosophy. Again, the phrase, "Shows the way," must surely mean that others are following the torch-bearer, from whom they get fire and light. In The Wisdom of the Ancients, Bacon, while explaining the parable of the torch-races honoring Prometheus, says: "... that the perfection of the sciences is to be looked for not from the swiftness or ability of any one inquirer but from a succession" (Works 155-56). Finally, and again in The Wisdom of the Ancients, Bacon speaks of the need for co-operation in the search for knowledge. Clearly having in mind the torch-races dedicated to Prometheus, Bacon says: ". . . that the victory may no longer depend upon the unsteady and wavering torch of each single man; but competition, emulation, and good fortune be brought to aid" (Works 156).

The foregoing juxtaposing of the myths of Pan, Perseus, Dionysius, and Prometheus with selected aphorisms from Book I of Francis Bacon's Novum Organum, convinces this writer that there is a definite relationship between these myths and Bacon's work. Francis Bacon dreamed of a new-found freedom for man, which was traceable to the age of ancient myths, when man was the undisputed monarch of nature, of knowledge, and of the universe as a whole. It was Bacon's hope to reinstate man in his original position of power; to restore him to his pre-eminent status. Meanwhile-and on the way to achieving his goal-Bacon strove to clarify and purify man's knowledge-process. This Bacon tried to achieve in his Novum Organum, supported by the wisdom and knowledge found in the vast and varied deposits of mythological lore.

\section{Works Cited}

Bacon, Francis. The New Organum and Related Writings. Ed. Fulton H. Anderson. New York: The Bobbs-Merrill Company, 1960. [Cited as NO.] 
Levine, Israel. Francis Bacon. Port Washington: Kennikat Press, 1970.

Spedding, James, Robert Leslie Ellis, Douglas Denon Heath, eds., The Works of Francis Bacon.

Vol. 13. Boston; Taggard and Thompson, 1864. [Cited as Works.]

\section{HISPANIC-CANADIAN CONNECTIONS \\ CANADIAN LITERATURE \#142-143}

Clearly and vividly, this collection of essays and poems raises important questions about cultural relations between Canada, Spain, Portugal, and Latin America.

Contributors include such writers as Jorge Etcheverry, Nain Nómez, Jesús Lopez-Pacheco, George McWhirter, George Woodcock, and Margarita Feliciano. Sherrill Grace writes on Lowry and Mexican act, Cynthia Messenger on Page and Bishop in Brazil, Nicola Vulpe on the Spanish Civil War in Canada, and Lake Sagaris on Chilean-Canadian writing. And more.

This collection is a valuable guide to current Hispanic-Canadian writing, and a valuable contribution to the study of Hispanic cultures abroad.

Cost per Journal: $\quad \$ 15.00$ plus -.-

$\checkmark$ Canadian orders: Add \$2.98 (GST, postage \& handling)

$\checkmark$ US orders:

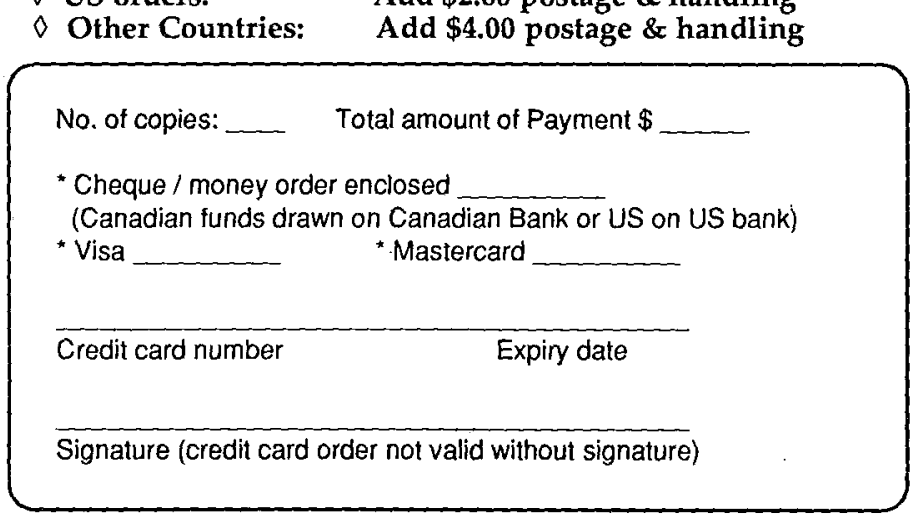

PLEASE PRINT YOUR NAME AND ADDRESS BELOW :

Send this form with payment to:

CANADIAN LITERATURE

University of British Columbia

Vancouver, BC V6T $1 Z 2$ Canada 